\title{
Role of Parathormone in Parthenogenesis of Rickets
}

\section{Abstract}

Parathormone (PTH) is composed of four glands embedded in the thyroid gland, but its function is mainly to keep calcium in the blood within normal range. It has got sensitive receptors that trigger the PTH to act in correcting serum calcium. As calcium is important for the normal functioning of many organs including vital organs like heart and brain, the PTH has to be prompt in maintaining calcium in the blood within normal. The function of PTH is to increase absorption of calcium in the gut and to reduce its excretion in the kidneys. When vitamin is low it leads to drop of calcium in the blood leading to calcium being mobilized from the high calcium reserves in the bone by the action of PTH. The loss of calcium in the bones leads to decalcification of the bones which makes the clinical features of rickets in the bones. In case of rickets bones become soft leading to bow legs in walking infants. All these features are the result of action of Parathormone as with the rise of PTH it is noticed the gradual increase of calcium together with high alkaline phosphatase as an indication of activity of rickets in infants and osteomalacia in the mothers. This review is to express the mechanism of causation of rickets and osteomalacia by the activity of the hyperparathyroidism which is secondary to hypocalcemia due to vitamin D deficiency in the breast feeding infant and their mothers where the latter is considered in the phase of biochemical osteomalacia.

Keywords: Rickets; Osteomalacia; Hyperparathyroidism (HPT)

\section{Elidrissy A}

College of Medicine Home, University of Science and Technology, Omdurman, Sudan

Corresponding author: Elidrissy A

” elidrissytazy@hotmail.com

Faculty of Paediatrics, College of Medicine Home, University of Science and Technology, Omdurman, Sudan.

Tel: 966553980280

Citation: Elidrissy A. Role of Parathormone in Parthenogenesis of Rickets. J Bone Rep Recomm. 2017, 3:2.

\section{Introduction}

Presentation of rickets in early stages, in the first year of life, is likely to be overlooked except when they develop the most serious presentations namely, convulsions, cardiomyopathy or myelofibrosis or chest infections [1-3]. It is only in a late first year and second year of life that obvious bony deformities are observed by family or medical practitioner especially in breastfed well-nourished growing infants. In the early [4,5] phase, we are likely to miss clinical features in the bones being not obvious, especially in well-nourished breastfed infants. The clinical signs of this deficiency are likely to be missed as noticed in two studies of ours thirty years apart, necessitating screening by chemical tests as an early sensitive test to diagnose rickets in early biochemical phase, in order to avoid potentially fatal complications like cardiomyopathy, myelofibrosis and convulsions. It is essential to stress on that maternal vitamin $D$ inadequacy is what triggers rickets, although it starts at birth, but remains occult in the infancy being well nourished, as it has been occult in the mother during pregnancy as well as the infant during the first year of life being $[2,3,6]$. The recommendations of supplementing the mothers with vitamin $D$ during pregnancy is considered a necessity and vital for having healthy new-born, especially in sunny countries. Hypocalcemia is commonest [7] and earliest feature of rickets, but it is not sustained as it is corrected by the hyperparathyroidism, the main actor in decalcifying the bones leading to the bony features of rickets. In this communication, the role of parathyroid in pathogenesis of rickets and its sequel is discussed through data collected from a biochemical and clinical study and by reviewing the literature.

\section{Methods}

Screening by biochemical monitoring of Calcium, Parathormone and alkaline phosphatase and phosphate levels in 136 cases of rickets, seen in a study reported previously. The infants diagnosed as rickets were divided into three groups according to age for the purpose of comparing the biochemical findings [1]: Group A below one year of age, group B between one year and two years and group $C$ above two years. Further, we divided each group into active and healed by the radiological evidence of 
healing showing thick line at the growing distal ends of the bones of the wrist. These biochemical markers were compared with that of the mothers. The level of Parathormone (PTH) in relation to activity and healing of bony features of rickets in relation to the level of 25OHD, Calcium (Ca), Phosphorous (Ph) and Alkaline Phosphatase (AP) is discussed.

\section{Results}

Parathyroid Hormone (PTH) level in the children with active rickets ranged from a mean of $99 \mathrm{pg} / \mathrm{ml}$ to $269 \mathrm{pg} / \mathrm{ml}$ (normal range from 9-65 pg/ml) accordingly all levels of PTH above $65 \mathrm{pg}$ were considered to have an early phase of rickets in infants and osteomalacia in the mothers. PTH was high in all three groups of age, but it was approximately threefold higher in group C (268 $\mathrm{pg} / \mathrm{ml})$ and less in group $B(200.66 \mathrm{pg} / \mathrm{ml})$ compared to group A $(99.03 \mathrm{pg} / \mathrm{ml})$. As shown in Figure 1. It is interesting that the lowest levels were in group $A$ (age below one year), which is the same early phase of mean calcium which was low at $1.88 \mathrm{mg} / \mathrm{dl}$ in group $A$. In the other two groups Parathormone levels were at 200 and $268 \mathrm{pg} / \mathrm{ml}$ respectively. As for PTH in the mothers it was 136,83 , and $90 \mathrm{pg} / \mathrm{ml}$ in group A, B and C respectively, these levels are high in comparison to the normal range of (9-65 $\mathrm{pg} / \mathrm{ml}$ ) and is considered an early degree of osteomalacia in the mother supported by the low vitamin D, but can be considered as occult or subclinical osteomalacia. These findings are in line with calcium and phosphate levels shown in Figures $\mathbf{2}$ and $\mathbf{3}$. The level of calcium was lower only in group A of infants (below one year of age).

\section{Parathyroid Hormone (PTH)}

Metabolism and functions: Parathyrin an 82 amino acid hormone is produced by the parathyroid glands and is decisive in maintaining calcium and phosphorus in balance. Deficiency of Parathormone results in abnormally low calcium in the blood (hypocalcemia). Excessive Parathormone leads to elevated calcium levels in the blood (hyperparathyroidism). This is done mainly by mobilizing calcium from bones and preventing its deposition in bone and cartilage to maintain serum calcium within normal level, but this leads to decalcification of bones

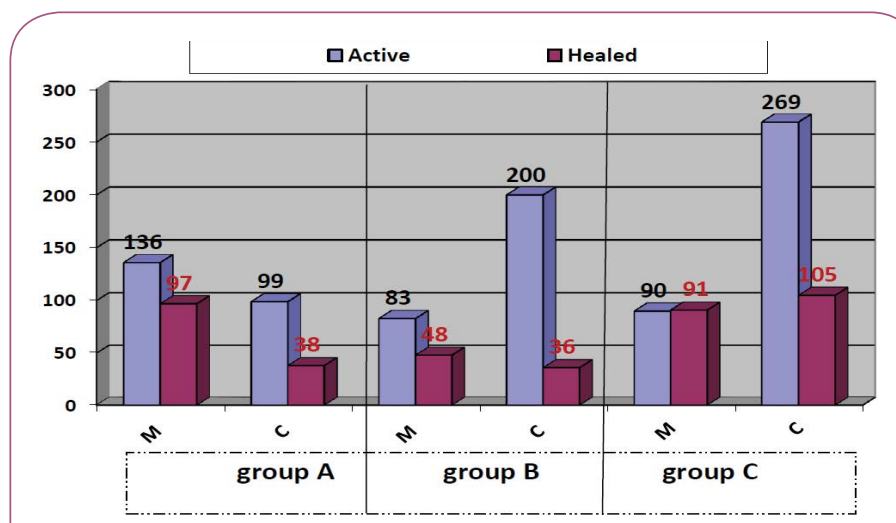

Figure 1

Serum Parathormone level9ptho $(\mathrm{pg} / \mathrm{ml})$ in Mother (M) and Child (C) active and healed rickets in groups $A(<1$ year), B (1-2 years) and C (>2 years), ref range (15-65 $\mathrm{pg} / \mathrm{l})$.

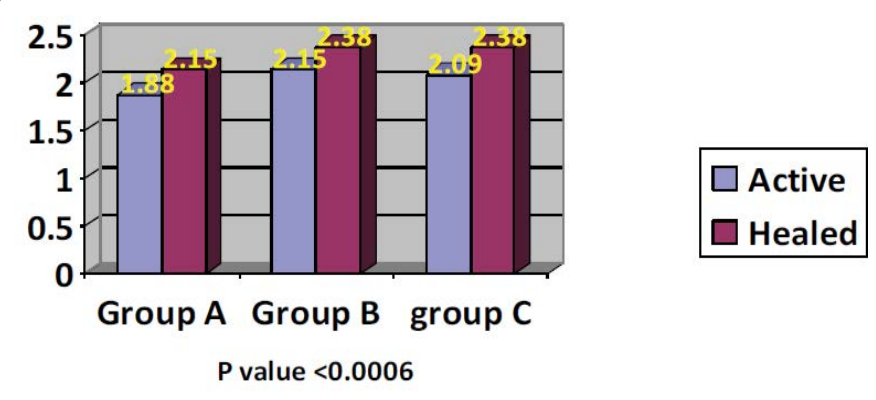

Figure 2 Serum calcium level $(\mathrm{mg} / \mathrm{dl})$ in active and healed rickets in group A ( $<1$ year), B (1-2 years) and C ( $>2$ years), ref range $2.1-2.5 \mathrm{mmol} / \mathrm{l}$.

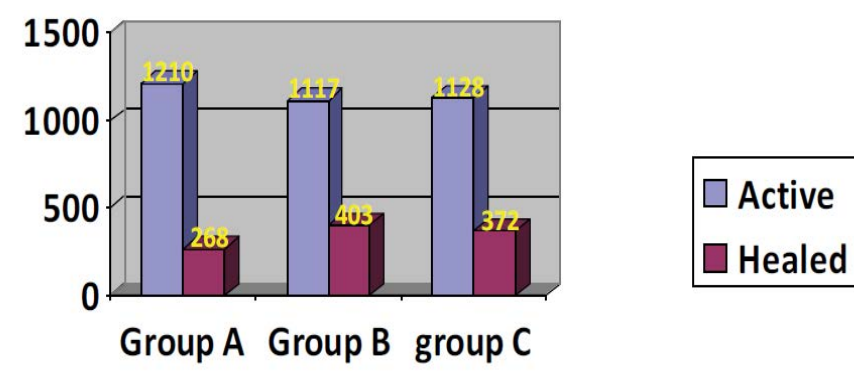

P value $<0.0001$

Figure 3 Serum alkaline phosphatase level (IU) in active and healed rickets in group $A$ ( $<1$ year), B (1-2 years) and C (>2 years), ref range $50-136 \mathrm{iu} / \mathrm{l}$.

which is termed, osteomalacia in adults and rickets in growing bones in children. There are reciprocal relations between the calcium and phosphorus concentrations in the blood which is important in maintaining the integrity of bones. Calcium and phosphorus homeostasis are maintained by the influence of parathyroid hormone on bone tissue and on the kidneys. An overabundance of the hormone causes demineralization of the bone tissue and the depletion of calcium and phosphorus from the body. Excess phosphorus is excreted by the kidneys. Softening of the bones and their eventual spontaneous fracture occur in hyperparathyroidism; tooth development is also impaired in hyperparathyroidism. The administration of parathyroid hormone corrects the symptoms of parathyroid deficiency. Removal of the glands results in convulsions (tetany), caused by the sharp decrease in the blood calcium concentration (from 9-11 to 4.5-5 mg percent). Blood phosphorus increases at the same time. Attacks of tetany may occur in animals with normal parathyroid when their food contains insufficient calcium. The size and functional condition of the parathyroid vary with the blood calcium. Serum Parathormone is high in active rickets in all three groups of age, but it is almost threefold higher in group $\mathrm{C}(268 \mathrm{p} / \mathrm{ml})$ and group B $(200.66 \mathrm{pg} / \mathrm{ml})$ compared to group A $(99.03 \mathrm{pg} / \mathrm{ml})$ of active rickets. This shows that with increased age during lack of vitamin $D$ the bones grow softer, demonstrated by bowing of the long weight bearing bones. 


\section{Physiologic effects of Parathyroid Hormone (PTH)}

Writing a task description for parathyroid hormone is straight forward: It is responsible for the homeostasis, of calcium ion concentrations in extracellular fluid when falls below normal, the duty of PTH is to mobilize calcium from the bone reserves bringing the blood calcium level back within the normal range. In conjunction with increasing calcium concentration, the concentration of phosphate ion in blood is boiled down. Parathyroid hormone accomplishes its task by stimulating at least three operations in the bones, small intestine and kidneys: 1) Mobilization of calcium from bone, although the mechanisms remain obscure, a well-documented effect of parathyroid hormone is to stimulate osteoclasts to reabsorb bone mineral, liberating calcium into the course of blood lineage. 2) Enhancing absorption of calcium from the small intestine: This would clearly help to raise blood levels of calcium. Parathyroid hormone stimulates this process, but indirectly by stimulating production of the active form of vitamin $D$ in the kidney. Vitamin $D$ induces synthesis of a calcium-binding protein in intestinal epithelial cells that facilitates efficient absorption of Ca in the gut. 3) Suppression of calcium loss in urine: In addition to stimulating fluxes of calcium into the blood from bone and intestine, parathyroid hormone puts a brake on the elimination of calcium in urine, thus conserving calcium in the lineage. This force is mediated by stimulating tubular reabsorption of $\mathrm{Ca}$. Some other effect of parathyroid hormone on the kidney is to cause loss of phosphate ions in urine.

\section{Control of secretion Parathyroid Hormone (PH)}

Parathyroid hormone is released in response to low extracellular concentrations of free calcium. Changes in blood phosphate concentration can be associated with changes in parathyroid hormone secretion, but this appears to be an indirect effect and phosphate per se is not a significant regulator of this hormone. When calcium concentration falls to a lower than the normal range, in that situation a steep increase in the secretion of the parathyroid hormone occurs. The lower levels of the hormone are secreted even when blood calcium levels are high. The parathyroid cell monitors the extracellular free calcium concentration via an integral membrane protein that functions as a calcium-sensing receptor. Vitamin active metabolite is what controls calcium and phosphate metabolism, but it is the hypocalcemia that stimulates the PTH to correct the calcium.

\section{PTH metabolism in active and healed rachitic infants and their mothers}

The total mean PTH level in children with active rickets was 199.8 $\mathrm{pg} / \mathrm{ml}$ and in healed rickets the mean PTH was $55.8 \mathrm{pg} / \mathrm{ml}$, the P value is 0.002 which is very significant as shown in Figure 1 . Mean Parathormone level in mothers (MPTH) of children (CPTH) with active rickets was 94 and healed rickets was $94.8 \mathrm{pg} / \mathrm{ml}$ which not significant as the mother seems to continue breastfeeding without having a chance to improve her PTH status. The infants with evidence of healing were already on vitamin $D$ supplements when seen.
PTH level in the children with active rickets ranged from a mean of $99-269 \mathrm{pg} / \mathrm{ml}$ (normal range from $9-65 \mathrm{pg} / \mathrm{ml}$ ). It is interesting that lower grades were in group a (age below one year) the mean PTH was $99.3 \mathrm{mpg} / \mathrm{ml}$ but the mean calcium level was low at 1.88 $\mathrm{mg} /$ decilitre. In the other two groups the very high Parathormone level at 200.66 and $268 \mathrm{pg} / \mathrm{ml}$, being long standing parathyroid activity induced correction of calcium in group $B$ and $C$ of active rickets which was 2.15 and $2.09 \mathrm{mg} / \mathrm{dl}$, respectively, otherwise the hypocalcemia if was not corrected, would have led to complications like stridor and cardiomyopathy with fatal results. With the increasing needs of calcium supply to these most critical and vital organs, namely the brain to preventing hypocalcemia convulsions and in the heart to maintain its contractility, and to prevent interference with its electrical activity and preventing cardiomyopathy leading to pump failure which is today being increasingly reported, the larynx might be affected by hypocalcemia causing stridor. As for the PTH level in the mothers of active rickets it was 136, 83 and $90 \mathrm{pg} / \mathrm{ml}$ in group A, B and C respectively, whereas in mothers of infants with healing rickets it was lower at: 97.48 and $91 \mathrm{pg} / \mathrm{ml}$, but not yet within the normal range except in group $B$ it was $48 \mathrm{pg} / \mathrm{ml}$ as seen in Figure 1 . The difference between these levels is significant in group $A$ and $B$ but not in group $C$. This high degree of parathyroid hormone in the mothers of group A supports that during pregnancy and lactation they were having a high degree of demand of calcium for the bone development of the foetus, leading to a degree of hypocalcemia enough to stimulate the parathyroid glands leading to hyperparathyroidism which can be explained by that the mothers were having an occult or biochemical osteomalacia. Lower vitamin $D$ levels in pregnant mothers in sunny countries were reported by us at birth [8] for the first time supporting our hypothesis that vitamin $D$ is low among mothers and it is what triggers rickets in their breastfeeding infants. It is now almost as [7-9] widely accepted that infantile rickets is due to maternal vitamin $D$ deficiency. These biochemical alterations in the mothers as seen in this cohort of mothers and babies needs further studies to substantiate, although it is widely accepted [7].

\section{PTH in disease states}

Both increased and decreased secretion of parathyroid hormone is considered as an agent of severe disease in humans. Excessive secretion of parathyroid hormone is taken in two forms:

1) Primary hyperparathyroidism is the effect of parathyroid gland increased secretions as in the adenoma. A common cause is parathyroid adenoma which secretes the hormone without control, which manifests as hypocalcemia, renal stones and decalcification of bone.

2) Secondary hyperparathyroidism is the situation where a primary disease outside of the parathyroid gland leads to increased secretion of Parathormone. Kidney disease as in renal failure, where it is unable to reabsorb calcium, leading to hypocalcemia, which leads to secondary hyperparathyroidism, ending as renal osteodystrophy (Von Recklinghausen's Disease) Nevertheless, in certain situations, treatment with parathyroid hormone can actually. 
3) In osteomalacia and rickets hyperparathyroidism is a response due to hypocalcemia caused by low vitamin $D$, as in deficiency or abnormal metabolism, or due dietary low calcium, Vitamin D deficiency due poor exposure to the sun is the commonest cause of rickets in children and osteomalacia in adult mainly women in developing world.

\section{PTH in pathogenesis of rickets}

Hypocalcemia is the first characteristic manifestation of rickets due to either, vitamin $D$ deficiency, or Low dietary intake of calcium, or impaired vitamin D metabolism. As the calcium is important for many vital functions in the body when it drops to a critical level of hypocalcemia, becomes life threatening. As a mechanism of self-correction from calcium is extracted from the major calcium reserve in bones, by the parathyroid glands are triggered to secrete Parathormone which accordingly mobilizes calcium from, the bones to the circulation, which is why hypocalcemia is the earliest manifestation of rickets and osteomalacia. The main objective is to make calcium available for all body tissue metabolisms, mainly the brain and heart to maintain survival. PTH has been constantly high and moved to increase while calcium is still needed [5] Atapattu et al. [10] have recently stated that vitamin D deficiency, based on PTH elevation, was best defined by a $250 \mathrm{HD}$ level of $<34 \mathrm{nmol} / \mathrm{l}$. Because deficient calcium supply often coexists with vitamin $D$ deficiency and both can independently cause nutritional rickets, a threshold for the skeletal effects of vitamin $D$ should not be based purely on 25OHD. Sethuraman et al. [11] found in congenital ichthyosis: Serum levels of $25(\mathrm{OH}) \mathrm{D} \leq 8 \mathrm{ng} / \mathrm{ml}$ and PTH ( $\geq 75 \mathrm{pg} / \mathrm{Ml}$ ) significantly increases the risk for development of rickets (OR=2.8; 95\% Cl=1.05-7.40; $\mathrm{P}=0.04$ ) in ichthyosis. Among the different types, $\mathrm{ARCl}$ (OR 4.83; 95\% Cl 1.74-13.45; p<0.01) and EI (OR 5.71; 95\% Cl 1.74-18.79; $p<0.01$ ) are at an increased risk of getting rickets. It seems the primary role of PTH is to maintain enough calcium for the heart and brain and others to keep the organism alive, and normally functioning even with fragile bones. As observed rickets is due to low vitamin D which is the major sustained of normal calcium, although rickets might be caused by lack of calcium in the diet [12-15] per se, as seen in Africa (Figures 4 and 5).

\section{Conclusion}

This relation between calcium and vitamin $D$ is of interest and you cannot say it is due to lack of one of them, it is like a brick and mud in building a wall, were both calcium and vitamin D are essential to build solid bones, definitely both are the essence of survival of heart and brain here come the priority of calcium needed to maintain its contractility, but vitamin D also has role in other fields like proliferation of bone marrow cells (Table 1). The Role PTH in rickets associated myelofibrosis: That in every case of rickets or osteomalacia hyperparathyroidism is a constant finding that is why a role of PTH in the development of the associated myelofibrosis seen with vitamin D deficiency is discussed. Kumbasar et al. [16] reported primary hyperparathyroidism causing myelofibrosis in a female presenting with fatigue, and bilateral knee pain and gait disturbance. Primary hyperparathyroidism was diagnosed

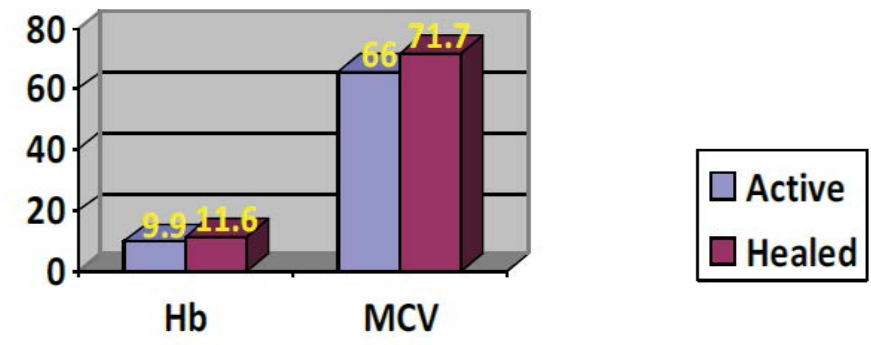

$P$ value $<0.0033,<0.0240$

Figure 4 Haemoglobin (g/dl) And mean corpuscular volume (femtoliter) in active and healed rickets.

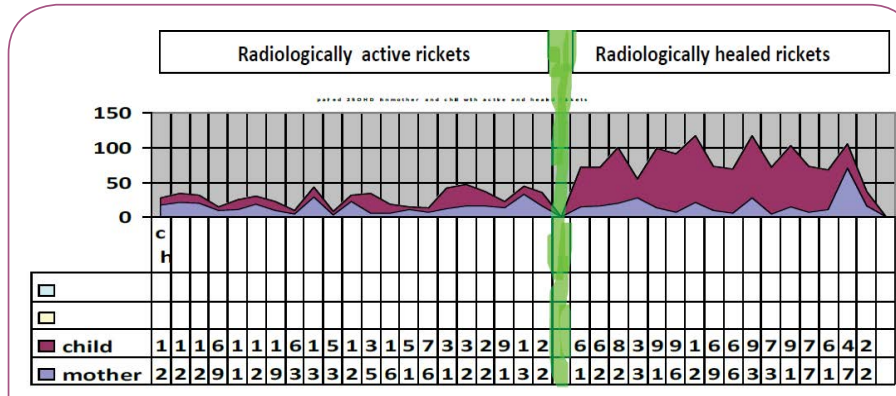

Figure $525 \mathrm{OHD}$ levels in infants with rickets together with their mother's ng/ml.

together with splenomegaly and anaemia. Bone marrow biopsy revealed myelofibrosis. A parathyroid adenoma was diagnosed and surgically excised. As early as three months after the operation, hematologic parameters improved along with bone markers without any other interference. The control bone marrow biopsy demonstrated well marked regression in marrow fibrosis. Her spleen also gradually decreased in size. These findings support that her myelofibrosis was the outcome of the primary hyperparathyroidism due to the adenoma, suggesting that hyperparathyroidism was the cause of myelofibrosis. Akyay et al. [17] also reported, that Primary hyperparathyroidism (PHP) and myelofibrosis are rare entities in childhood, as well as myelofibrosis secondary to PHP is exceedingly rare that is why he reported a fifteen year old male child who presented with generalized weakness, vomiting, and pallor. A parathyroid adenoma was discovered along the left distal parathyroid gland, so PHP was diagnosed in addition to hepato-splenomegaly and pancytopenia. Bone marrow biopsy revealed grade 3-4 reticulin fibrosis. As early as 2 months after the left distal Para thyroidectomy, hematologic parameters improved without any other interference. His liver and spleen also gradually decreased in size. They suggested that the pancytopenia was a consequence of the myelofibrosis caused by primary hyperparathyroidism. Calvi [18] reported that PTH through activation of the PTH/ PTHrP receptor (PTH1R) in osteoplastic cells could alter the Hematopoietic Stem Cell (HSC) niche resulting in HSC expansion in vivo and in vitro and improving dramatically the survival of mice receiving bone marrow transplants. This change may be the 
Table 1 Bone related biochemical funding's in children with active rickets and their mothers.

\begin{tabular}{|c|c|c|c|c|c|c|c|}
\hline $\begin{array}{l}\text { Children with active Rickets } \\
\text { group A, B, C \& total }\end{array}$ & & & & $\begin{array}{l}\text { Mothers of children with active } \\
\text { rickets }\end{array}$ & & & \\
\hline PTH Pg/ml & $\mathrm{Ca}$ & $\mathrm{Ph}$ & Alk pho iu & PTH Pg/ml & $\mathrm{Ca}$ & $\mathrm{Ph}$ & Alk pho iu \\
\hline A 99.03 & 1.88 & 1.13 & 1210 & 38.8 & 2.15 & 1.793 & 268 \\
\hline В 200 & 2.15 & 1.04 & 1117 & 36.9 & 2.38 & 1.724 & 463 \\
\hline 2268 & 2.09 & 1.01 & 1128 & 104.7 & 2.38 & 1.57 & 372 \\
\hline Total: 189.7 & 2.04 & 1.06 & 1151 & Total: 56.7 & 2.3 & 1.69 & 347.67 \\
\hline
\end{tabular}

fibrosis observed in association with myelofibrosis, still there might be a supporting mechanism to explain why only very few cases of hyperparathyroidism develop myelofibrosis. Recently, Brunner et al. [19] found that primary hyperparathyroidism is associated with increased circulating bone marrow-derived progenitor cells. In accession to the PTH was shown to support survival of progenitor cells in bone marrow. The release of progenitor cells occurs in physiological and pathological conditions and was demonstrated to contribute to neo-vascularization in tumours and ischemic tissues. This is another role played by PTH supporting that hyperparathyroidism is what is causing myelofibrosis in all the cases reviewed. This notion is also supported by the complete recovery after removal of a parathyroid adenoma in a reported case by Bhadada et al. [20] who found that anaemia is common in patients with symptomatic PHPT, and was associated with marrow fibrosis in most of the patients who have had bone biopsy. Both anaemia and marrow fibrosis improved by curative Para thyroidectomy, but improvement in anaemia was noticeable only in those who had marrow fibrosis at presentation. Sikole [21] suggested that PTH, when in excessive amounts, interferes with normal erythropoiesis by down regulating the erythropoietin receptors on erythroid progenitor cells in the bone marrow. Therefore, physiologic concentrations of EPO can no longer sustain normal red cell counts, so normocytic and normochromic anaemia ensues. In primary Hyperparathyroidism (HPT), this effect is observed with very high concentrations of PTH. In secondary HPT during chronic renal failure, this effect is more pronounced because erythropoietin synthesis is impaired. From these data, it can categorically say that myelofibrosis in rickets is caused by hyperparathyroidism whether primary or secondary. This was stressed by myelofibrosis in rickets is caused by secondary hyperparathyroidism, as it was reported in primary hyperparathyroidism, especially in the cases of parathyroid adenoma showing complete recovery postoperatively [22]. Myelofibrosis associated with chronic renal failure is also having associated hyperparathyroidism with almost non-functioning vitamin $\mathrm{D}$. In this situation, it can be stated that hypovitaminosis $D$ and hyperparathyroidism do not have a synergistic role in the development of myelofibrosis, it might that there is a critical level of each of the metabolites up and down, that precipitates the myelofibrosis supported and explained by that only very few of vitamin D deficiency cases with hyperparathyroidism will develop myelofibrosis. The cases reported are enough to think of anaemia in rickets has got to do with the hyperparathyroidism rather than anything else. 


\section{References}

1 Elirissy ATH, Sandokji AM, Al-Magamsi MSF, Al-Hawsawi ZM, AlHujaili AS, et al. (2012) Nutritional rickets in Almadinah: presentation and associated factors. JTU Med Sci 7: 35-40.

2 Elidrissy ATH, Alharbi K (2013) Cardiomyopathy in infants Hypocalcemia rachitic cardiomyopathy in infants. J Saudi Heart Assoc 25: 25-33.

3 Elidrissy ATH, Zolaly MA, Hawsawi ZM (2012) Anaemia in infants with vitamin $D$ deficiency rickets: $A$ single centre experience and literature review. J Appl Hematol 3: 39-43.

4 Elidrissy ATH (1986) Nutritional status of children with rickets in Riyadh. Ann Saudi Med 6: 101-110.

5 Elidrissy ATH (2011) Vitamin D Deficiency Rickets (VDDR) is not related to Protein Calorie Malnutrition (PCM). Glob Adv Res 3: 11.

6 Elirissy ATH (2014) Vitamin D deficiency triggering rickets in their new-born infants.

7 Elidrissy ATH (2016) The return of congenital rickets, are we missing occult cases? Calcif Tissue Int Sep 99: 227-236.

8 Elidrissy AT, Sedrani SH (1984) Vitamin D deficiency in mothers of rachitic infants. Calcify Tissue Int 36: 266-268.

9 Serenius F, Elidrissy AT, Dandona P (1984) Vitamin D nutrition in pregnant women at term and in newly born babies in Saudi, Arabia. J Clin Pathol 37: 444-447.

10 Atapattu N, Shaw N, Högler W (2013) Relationship between serum 25-hydroxyvitamin $D$ and parathyroid hormone in the search for a biochemical definition of vitamin D deficiency in children. Paediatr Res 74: 552-556.

11 Sethuraman G, Sreenivas V, Yenamandra VK, Gupta N, Sharma VK (2014) Threshold levels of $25(\mathrm{OH}) \mathrm{D}$ and parathyroid hormone for impaired bone health in children with congenital Ichthyosis in type IV and V skin. Br J Dermatol 172: 208-214.
12 Pettifor JM, Ross FP, Travers R, Glorieux FH, DeLuca HF (1981) Dietary calcium deficiency: a syndrome associated with bone deformities and elevated serum 1,25-dihydroxyvitamin D concentrations. Metab Bone Related Res 2: 301-315.

13 Marie PJ, Pettifor JM, Ross FP, Glorieux FH (1982) Histological osteomalacia due to dietary calcium deficiency in children. $\mathrm{N}$ Engl J Med 307: 584-588.

14 Okonofua F, Gill DS, Alabi ZO, Thomas M, Bell JL (1991). Rickets in Nigerian children: a consequence of calcium malnutrition. Metabolism 40: 209-213.

15 Thacher TD, Ighogboja SI, Fischer PR (1997). Rickets without vitamin D deficiency in Nigerian children. Ambul Child Health 3: 56-64.

16 Kumbasar B, Taylan I, Kazancioglu R, Agan M, Yenigun M (2004) Myelofibrosis secondary to hyperparathyroidism. Exp Clin Endocrinol Diabetes 112: 127-130.

17 Akyay A, Cihangiroglu G, Özkan Y, Deveci U, Bahceci S, et al. (2013) Primary hyperparathyroidism as an extremely rare cause of secondary myelofibrosis in childhood. J Pediatr Endocrinol Metab 26: $1185-1188$.

18 Calvi LM (2015) Osteoblastic: Activation in the hematopoietic stem cell niche. Ann N Y Acad Sci 1: 63-77.

19 Brunner S, Theiss HD, Murr A, Negele T, Franz WM (2007) Primary hyperparathyroidism is associated with increased circulating bone marrow-derived progenitor cells. Am J Physiol Endocrinol Metab 293: E1670-E1675.

20 Bhadada SK, Bhansali A, Ahluwalia J, Chanukya GV, Behera A (2009) Dutta parathyroidectomy. Clin Endocrinol 70: 527-532.

21 Sikole A (2000) Pathogenesis of anaemia in hyperparathyroidism. MED Hypotheses 54: 236-238.

22 Elidrissy ATH (2016) Myelofibrosis associated, with rickets, is it hyperparathyroidism the triggering agent or vitamin $D$ and hypocalcemia or hypophosphatemia? Int J Clin Endocrinol Metab 2: 19-23. 